\title{
High fat diet-induced oxidative stress blocks hepatocyte nuclear factor $4 a$ and leads to hepatic steatosis in mice
}

\author{
Dongsheng $\mathrm{Yu}^{1}$ | Gang Chen ${ }^{2}$ | Minglin $\operatorname{Pan}^{3}$ | Jia Zhang ${ }^{1}$ | Wenping $\mathrm{He}^{1}$ | \\ Yang Liu ${ }^{4,5}$ | Xue Nian ${ }^{1}$ | Liang Sheng ${ }^{1}$ (D) | Bin $\mathrm{Xu}^{6}$
}

${ }^{1}$ Department of Pharmacology, School of Basic Medical Science, Nanjing Medical University, Nanjing, Jiangsu, China

2 Department of Hepatobiliary Surgery, The First Affiliated Hospital of Wenzhou Medical University, Wenzhou, Zhejiang, China

${ }^{3}$ Department of Endocrinology, The Second Affiliated Hospital of Nanjing Medical University, Nanjing, Jiangsu, China

${ }^{4}$ Department of Gastroenterology and Hepatology, Zhongda Hospital, Nanjing, Jiangsu, China

${ }^{5}$ Institute of Gastroenterology and Hepatology, School of Medicine, Southeast University, Nanjing, Jiangsu, China

${ }^{6}$ Department of Internal Medicine, Division of Metabolism, Endocrinology and Diabetes, University of Michigan Medical Center, Ann Arbor, Michigan

\section{Correspondence}

Liang Sheng, PhD, Department of Pharmacology, School of Basic Medical Science, Nanjing Medical University, 101 Longmian Rd, Nanjing, Jiangsu 211166, China. Email: Igsheng@njmu.edu.cn Bin $\mathrm{Xu}, \mathrm{PhD}$, Department of Internal Medicine, Division of Metabolism, Endocrinology and Diabetes, University of Michigan Medical Center, Ann Arbor, MI 48109-56788.

Email: bxu@umich.edu

\section{Funding information}

National Natural Science Foundation of China, Grant number: 81400613; Natural Science Foundation of Jiangsu Province, Grant numbers: BK20140901, BK2015041792
Nonalcoholic fatty liver disease (NAFLD) is the most common form of chronic liver disease with manifestation of over-accumulation of fat in liver. Increasing evidences indicate that NAFLD may be in part caused by malfunction of very low density lipoprotein (VLDL) secretion. Hepatocyte nuclear factor $4 a$ (HNF4a), a nuclear receptor protein, plays an important role in sustain hepatic lipid homeostasis via transcriptional regulation of genes involved in secretion of VLDL, such as apolipoprotein B (ApoB). However, the exact functional change of HNF4a in NAFLD remains to be elucidated. In the present study, we found that high fat diet (HFD) induced cytoplasmic retention of HNF4a in hepatocytes, which led to down-regulation of hepatic $A p o B$ expression and its protein level in serum, as well as reduced secretion of VLDL. We further revealed that oxidative stress, elevated in fatty liver, was the key factor inducing the cytoplasmic retention of HNF4a in hepatocytes by activating protein kinase $\mathrm{C}(\mathrm{PKC})$-mediated phosphorylation in HNF4a. Thus, our findings reveal a novel mechanism underlying HFD-induced fatty liver that oxidative stress impairs function of HNF4a on ApoB expression and VLDL secretion via PKC activation, eventually promoting fat accumulation in the liver. Therefore, oxidative stress/PKC/ HNF4a pathway may be a novel target to treat diet-induced fatty liver.

\section{KEYWORDS}

apolipoprotein B, HNF4a, NAFLD, oxidative stress, protein kinase C, VLDL secretion

Abbreviations: ApoB, apolipoprotein B; CAT, catalase; FFA, free fatty acid; $\mathrm{H}_{2} \mathrm{O}_{2}$, hydrogen peroxide; HFD, high fat diet; HNF4a, hepatocyte nuclear factor 4a; LDL, low density lipoprotein; LPS, lipopolysaccharide; MTTP, microsomal triglyceride transfer protein; NAFLD, nonalcoholic fatty liver disease; NRF2, nuclear factor-like 2; PA, palmitate; PKC, protein kinase C; PPARa, peroxisome proliferator-activated receptor-a; SOD, superoxide dismutase; TAG, triglycerides; VLDL, very low density lipoprotein. 


\section{1 | INTRODUCTION}

Nonalcoholic fatty liver disease (NAFLD) is caused by over-deposit of hepatic fat in the absence of excess alcohol intake, and often associated with obesity, insulin resistance, and metabolic syndrome (Gaggini et al., 2013; Loomba \& Sanyal, 2013). Nonalcoholic steatohepatitis (NASH), characteristic of liver damage after steatosis, is the more virulent form of NAFLD, and can lead to cirrhosis (Michelotti, Machado, \& Diehl, 2013). Hepatic lipid levels are the results of balance between multiple physiological processes, including lipid uptake, lipogenesis, fatty acid-oxidation, and very low density lipoprotein (VLDL) secretion. Free fatty acid (FFA) flux from lipolysis in adipose tissue, dietary intake, and de novo lipogenesis are usually either oxidized in the mitochondria ( $\beta$-oxidation) or esterified to triglycerides (TAG), which in turn are packaged as VLDL for export (Browning \& Horton, 2004; Cohen, Horton, \& Hobbs, 2011). VLDL secretion is the main pathway to transport hepatic TAG to periphery tissues. When the biosynthesis of TAG exceeds the rate of FFA oxidation of TAG secretion via VLDL, excessive TAG accumulates into lipid droplets in the liver resulting in steatosis. Steatosis may also originate when the packaging process of TAG into VLDL particles is impaired due, for instance, to hepatitis C virus infection (Gupte, Dudhade, \& Desai, 2006; Perlemuter et al., 2002) or genetic mutations in apolipoprotein $\mathrm{B}(\mathrm{ApoB})$, and microsomal triglyceride transfer protein (MTTP) (Berriot-Varoqueaux, Aggerbeck, Samson-Bouma, \& Wetterau, 2000; Tanoli, Yue, Yablonskiy, \& Schonfeld, 2004), the important component of VLDL and key enzyme catalyzing VLDL synthesis, respectively. Notably, high fat diet (HFD) also inhibits the VLDL secretion in rodents (Cahova, Dankova, Palenickova, Papackova, \& Kazdova, 2012; Francone, Griffaton, \& Kalopissis, 1992; Oussadou, Griffaton, \& Kalopissis, 1996; Yang et al., 2015). Over-consumption of fat is the more widespread in the development of NAFLD compare to hepatitis $C$ virus infection or genetic mutation. However, how HFD affects hepatic VLDL production remains to be elucidated.

Hepatocyte nuclear factor $4 a$ (HNF4a, NR2A1) is a highly conserved member of the nuclear receptor superfamily and plays important roles in both liver early development and regulating hepatocyte proliferation in adults (Alder et al., 2014; Bonzo, Ferry, Matsubara, Kim, \& Gonzalez, 2012; Walesky et al., 2013). HNF4a is a master regulator of liver gene expression, and critically regulates multiple hepatic metabolic pathways (Martinez-Jimenez, Kyrmizi, Cardot, Gonzalez, \& Talianidis, 2010; Odom et al., 2004). Liverspecific conditional knockout of HNF4a in adult mice led to severe steatosis in association with disruption of VLDL secretion (Hayhurst, Lee, Lambert, Ward, \& Gonzalez, 2001; Yin et al., 2011; Yin, Ma, Ge, Edwards, \& Zhang, 2011), and misregulation of ApoB and MTTP expression. Although HNF4a has important functions in maintaining hepatic lipid homeostasis, its roles in the development of HFD-induced NAFLD remain to be elucidated.

In this study, we analyzed the fatty liver induced by HFD in mice, demonstrating that the cytoplasmic retention of hepatic
HNF4a is caused by the enhanced oxidative stress in liver, which mediates phosphorylation of HNF4a at Ser78 by activating PKCs. The phosphorylative modification prevents the transportation of HNF4a into nucleus via importin. Thus, the impaired transcriptional activity of $\mathrm{HNF} 4 \mathrm{a}$ reduces expression of $\mathrm{ApoB}$ and subsequently decreases the VLDL secretion. As the result, more TAG accumulates in liver and deteriorates the NAFLD. The present investigation reveals a new mechanism that oxidative stress promotes NAFLD development.

\section{MATERIALS AND METHODS}

\section{1 | Animals}

Male C57BL/6 and ob/ob mice were purchased from Model Animal Research Center of Nanjing University, and housed in a pathogenfree barrier facility with a $12 \mathrm{hr}$ light/dark cycle and free access to food, and water. At the age of 8 weeks, WT mice were fed with either a standard laboratory rodent chow diet (Chow) providing $3.85 \mathrm{kcal} / \mathrm{g}$ of energy ( $10 \%$ fat, $20 \%$ proteins, and $70 \%$ carbohydrates) or a HFD providing $5.24 \mathrm{kcal} / \mathrm{g}$ of energy $(60 \% \mathrm{fat}, 20 \%$ carbohydrate, $20 \%$ protein; supplemented with $1 \%$ cholesterol; FBSH Biopharmaceutical Co., Ltd., Shanghai, China) for 12 weeks. Mice in other groups were fed HFD for 4 or 8 weeks until the age of 20 weeks, ob/ob mice were always fed with chow diet. Mice were sacrificed during the light phase without food deprivation. Serum and livers were isolated and stored in liquid nitrogen. All animal husbandry and procedures for experiments were approved by the Animal Experiment Committee of the Nanjing Medical University and complied with the guidelines of the Nanjing Medical University's Regulations of Animal Experiments.

\subsection{Assay for TAG, VLDL, and VLDL-TAGs in serum, liver, and medium of hepatocytes}

VLDL levels in serum and medium were measured using mouse VLDL ELISA kit (Luyuan Bode Biological technology, Beijing, China). VLDL and low-density lipoprotein (LDL) in serum were precipitated by phosphotungstic acid/ $\mathrm{Mg}^{2+}$ reagent (Demacker, Hessels, ToenhakeDijkstra, \& Baadenhuijsen, 1997), whereas LDL was selectively precipitated by polyvinylsulphate/polyethyleneglycol methyl ether (Demacker, Hijmans, Brenninkmeijer, Jansen, \& Van't Laar, 1984). The content of TAG in serum and corresponding supernatant lack of LDL or LDL plus VLDL was determined enzymatically with commercial TAG assay kits (GPO-PAP; Dong'ou Bioengineering Co. Ltd, Wenzhou, China), and subsequently the content of TAG in VLDL could be calculated. VLDL-TAGs in medium secreted by cultured hepatocytes were directly measured by TAG assay kits, for VLDL was the unique carrier of TAG in culture medium of hepatocytes. For liver TAG assay, liver samples were homogenized in $1 \%$ acetic acid and extracted by chloroform-methanol (2:1). The organic phase was evaporated in a new tube. Lipid residues were dissolved in isopropanol and measured using the TAG assay kit. 


\section{3 | Reactive oxygen species (ROS) assays}

Liver samples were homogenized in a lysis buffer, mixed with dihydroethidium fluorescent probe (DHE, 37291, Sigma-Aldrich, Shanghai, China) to a final probe concentration of $5 \mu \mathrm{M}$ for $30 \mathrm{~min}$ at $37^{\circ} \mathrm{C}$. DHE fluorescence was measured using a BioTek Synergy 2 Multi-Mode Microplate Reader (358 nm excitation and $461 \mathrm{~nm}$ emission) (Kalyanaraman et al., 2012).

\section{4 | Hepatic superoxide dismutase (SOD), catalase (CAT) activity, and lipid peroxidation content assay}

Total hepatic SOD and CAT activities were measured on homogenized liver tissue using commercial assay kits according to the manufacturer's instructions (Nanjing Jiancheng Bioengineering Institute, Nanjing, China). Levels of malondialdehyde (MDA), a product of lipid peroxidation, were measured based on reaction between MDA and thiobarbituric acid (TBA) with commercial kit from Nanjing Jiancheng Bioengineering Institute (Lv et al., 2017). Briefly, $500 \mu \mathrm{l}$ of tissue sample was mixed with $2 \mathrm{ml}$ of $0.6 \%$ TBA in acetic acid, after $40 \mathrm{~min}$ incubation at $95^{\circ} \mathrm{C}$, the final reaction mixture was centrifugated at $4,000 \mathrm{rpm}$ for $10 \mathrm{~min}$. MDA levels were determined at wavelengths of $532 \mathrm{~nm}$. The enzymatic activities were recorded as units per milligram of protein ( $\mathrm{U} / \mathrm{mg}$ protein). Values obtained were the average of three independent measurements.

\section{$2.5 \mid$ Cell culture}

The human hepatoblastoma/hepatocellular carcinoma HepG2 cell line (ATCC HB-8065) and COS-7 cells line (Institute of Biochemistry and Cell Biology, GNO-2, Shanghai, China) were maintained at $37^{\circ} \mathrm{C}$ in $5 \%$ $\mathrm{CO}_{2}$ in Dulbecco's modified eagle medium (DMEM) containing $10 \%$ fetal bovine serum (FBS) plus penicillin $(100 \mathrm{U} / \mathrm{ml})$ and streptomycin $(100 \mu \mathrm{g} / \mathrm{ml})$. Hepatocytes were isolated from 10-week old male mice and cultured in Williams' medium E (WME) supplemented with 6\% FBS as previously described (Sheng et al., 2012). After seeded in plates $\left(5 \times 10^{6}\right.$ cells $/ 10 \mathrm{~cm}$ dishes) for $5 \mathrm{hr}$, hepatocytes were serum deprived and treated by stimuli including TNFa $(10 \mathrm{ng} / \mathrm{ml})$, palmitate (PA, $250 \mu \mathrm{M})$, lipopolysaccharide (LPS, $1 \mu \mathrm{g} / \mathrm{ml})$, hydrogen peroxide $\left(\mathrm{H}_{2} \mathrm{O}_{2}\right.$, $1 \mu \mathrm{M})$, glucose $(30 \mathrm{mM})$ or insulin $(100 \mathrm{nM})$ for further $24 \mathrm{hr}$. Dexamethasone $(100 \mathrm{nM})$ was added $6 \mathrm{hr}$ before harvesting. Pan-PKC inhibitor Go6983 and proteasome inhibitor MG132 were purchased from Selleck Chemical (Houston, TX), nuclear transport receptor importin- $\beta$ inhibitor importazole (\#SML0341) was obtained from Sigma-Aldrich.

\subsection{Immunoprecipitation and immunoblotting}

COS-7 cells, hepatocytes or frozen liver samples were homogenized in ice-cold lysis buffer $(50 \mathrm{mM}$ Tris- $\mathrm{HCl}, \mathrm{pH} 7.5,0.5 \%$ Nonidet P-40, $150 \mathrm{mM} \mathrm{NaCl}, 2$ mM EGTA, $1 \mathrm{mM} \mathrm{Na}_{3} \mathrm{VO}_{4}, 100 \mathrm{mM}$ $\mathrm{NaF}, 10 \mathrm{mM} \mathrm{Na} \mathrm{P}_{2} \mathrm{O}_{7}, 1 \mathrm{mM}$ phenylmethylsulfonyl fluoride, $10 \mathrm{mg} / \mathrm{ml}$ aprotinin, $10 \mathrm{mg} / \mathrm{ml}$ leupeptin). Cell or tissue extracts were incubated with primary antibody of HNF4a at $4^{\circ} \mathrm{C}$ for $2 \mathrm{hr}$ and with protein A-sepharose beads (P001-3, 7-Sea Biotech, Shanghai, China) for an additional hour at $4^{\circ} \mathrm{C}$. The immunocomplexes adsorbed on the protein A-sepharose beads were washed three times with lysis buffer and boiled at $95^{\circ} \mathrm{C}$ for $5 \mathrm{~min}$ in loading buffer $(50 \mathrm{mM}$ Tris- $\mathrm{HCl}, \mathrm{pH}$ 6.8, 2\% SDS, 2\% mercaptoethanol, $10 \%$ glycerol, $0.005 \%$ bromphenol blue). The proteins in cytoplasm and nucleus were extracted by kit from Beyotime Institute of Biotechnology (Shanghai, China). Serum samples were directly mixed with loading buffer for boiling. Protein was separated by SDS-PAGE, immunoblotted with indicated primary antibodies and horseradish peroxidase-conjugated secondary antibodies (1:5000 dilution; Anti-Rabbit IgG, A21020; Anti-mouse IgG, A21010; Abbkine, Wuhan, China) and visualized using Tanon5200 Chemiluminescence Imager (Tanon, Shanghai, China) with ECL Western blotting substrate (Biovision, Milpitas, CA). Rabbit polyclonal antibodies used were as follows: phospho-serine antibody (1:1000 dilution; ab9332, Abcam, Shanghai, China), HNF4a (1:1000 dilution; ab199431, Abcam), ApoB (1:1000 dilution; ab31992, Abcam), MTTP (1:1000 dilution; ab75316, Abcam), acetylated-lysine (1:2000 dilution; 9441S, Cell Signaling Technology, Shanghai, China). Mouse monoclonal antibodies were as follows: $\beta$-actin (1:4000 dilution; 200068-8F10, Zen BioScience, Chengdu, China) and tubulin (1:4000 dilution; 4466, Cell Signaling Technology).

\subsection{Quantitative real-time PCR (qRT-PCR)}

Total RNAs were extracted from livers or primary hepatocytes and used to measure the mRNA abundance using Absolute TM QPCR SYBRGreen kits (Thermo Scientific, Waltham, MA) and a 7500 Fast Real-Time PCR System (Thermo Fisher Scientific Inc.). The primer sequences were as follows: ApoB, 5'-CCAGAGTGTGGAGCTGAATGT-3' (forward) and 5'-TTGCTTTTTAGGGAGCCTAGC-3' (reverse); MTTP, 5'-AGCCAGTGGGCATAGAAAATC-3' (forward) and 5'-GGTCACTTTACAATCCCCAGAG-3' (reverse); HNF4a, 5'-ATGCGACTCTCTAAAACCCTTG-3' (forward) and 5'-ACCTTCAGATGGGGACGTGT-3'(reverse); SOD1, 5'-AACCAGTTGTGTTGTCAGGAC-3' (forward) and 5'-CCACCATGTTTCTTAGAGTGAGG-3' (reverse); CAT, 5'-AGCGACCAGATGAAGCAGTG-3' (forward) and 5'-TCCGCTCT CTGTCAAAGTGTG-3' (reverse); NRF2, 5'-TCTTGGAGTAAGTCGAGAAGTGT-3' (forward) and 5'-GTTGAAACTGAGCGAAAAAGGC-3' (reverse); 36B4, 5'-AAGCGCGTCCTGGCATTG TCT-3' (forward) and $5^{\prime}$-CCGCAGGGGCAGCAGTGGT-3'(reverse);

\section{8 | Vectors used}

pGL3-ApoB containing ApoB promoter was kindly provided by Wei, Dongping (The First Hospital of Nanjing, Nanjing, Jiangsu, China). pcDNA3.0-HNF4a was a present from Rui, Liangyou (University of Michigan, MI), which is used to construct HNF4a mutant (S78A and S78D) by Shanghai Generay Biotech Co., Ltd. A PCR-generated EcoR1/Xho1 fragment encoding mouse PKC $\delta$ and 
$\mathrm{PKC} \varepsilon$ from mouse cDNA were inserted into the EcoR1/Xho1digested pcDNA3.1(+) (Invitrogen, Shanghai, China). The primers for cloning are as follows: PKC $\delta, 5^{\prime}$-GTCCAGTGTGGTGGAATTCGCCACCATGGCACCCTTCCTGCGCATCT-3' (forward) and 5 '-CGGGCCCTCTAGACTCGAGTTAAATGTCCAGGAATTG CTCA-3' (reverse); PKCE, 5'-GTCCAGTGTGGTGGAATTCGCCACCATGGTAGTGTTCAATGGCCTTC-3' (forward) and 5'-CGGGCC CTCTAGACTCGAGTCAGGGCATCAGGTCTTCACCA-3'(reverse).

\section{9 | Luciferase assays}

HepG2 cells were seeded onto 24 -well plates, grown to $40-50 \%$ confluency, and transfected with luciferase reporter plasmids using polyethylenimine $(1 \mathrm{mg} / \mathrm{ml})$. Briefly, cells were incubated for $4 \mathrm{hr}$ in $250 \mu \mathrm{l}$ of serum-free DMEM containing pGL3-ApoB (200 ng), pRL-TK-Renilla (10 ng), pcDNA3.0-Flag-HNF4a (40 ng), and polyethylenimine $(3 \mu \mathrm{l})$ and then grown in DMEM with $10 \%$ FBS for $24 \mathrm{hr}$. The cells were subsequently incubated for $24 \mathrm{hr}$ in the complete medium described above supplemented with $\mathrm{H}_{2} \mathrm{O}_{2}(1 \mu \mathrm{M})$ or $\mathrm{Go6983}$ $(1 \mu \mathrm{M})$. Luciferase activity was measured using the Dual-luciferase reporter assay System (Promega, Madison, WI) and normalized to Renilla luciferase values. Measurements for three biological replicates were taken in triplicate and averaged.

\subsection{0 | Immunofluorescence staining}

Primary hepatocytes were seeded on 18-mm glass coverslips in 12 -well plates at a density of $5 \times 10^{4}$ cells/well and treated as described above. After treatment, cells were fixed in $4 \%$ paraformaldehyde, and stained for indirect immunofluorescence using an antiHNF4a primary antibody (1:200 dilution), followed by an Alexa Fluor 488 goat anti-rabbit secondary antibody (1:200 dilution, Abcam). HNF4a proteins and 4,6-diamidino-2-phenylindole (DAPI)-stained nuclei were visualized using an Olympus IX81 inverted fluorescence microscope. Combined DAPI/Alexa Fluor 488 images were generated using an Olympus DP70 digital camera with DP Controller and DP Manager software.

\subsection{1 | Statistical analysis}

Data were presented as mean \pm S.E. Data between groups were analyzed by using unpaired two-sided Student's $t$-test or one-way ANOVA (GraphPad Prisim, La Jolla, CA). $p<0.05$ was considered statistically significant.

\section{3 | RESULTS}

\subsection{HFD induces hepatic TAG accumulation but decreases VLDL secretion in mice}

The earliest stage of NAFLD is hepatic steatosis, characterized by the deposition of TAG in lipid droplets of hepatocytes (Cohen et al., 2011). Consistent to previous reports (Cahova et al., 2012; Francone et al.,
1992; Oussadou et al., 1996), hepatic TAG level in C57BL/6 mice was significantly increased after 4-week HFD-feeding and further elevated (12-fold) with 12-week HFD-feeding (Figure 1a). Serum TAG level was not significantly increased until 12-week HFD-feeding (Figure 1b). Since VLDL secretion is the major export pathway for hepatic TAGs (Cohen et al., 2011), we next examined the profiles of serum level of VLDL under HFD-feeding. Interestingly, the serum level of VLDL was significantly reduced up to 12 -week HFD-feeding (Figure 1c). To determine VLDL production rate from the liver, we measured serum VLDL, and VLDL-TAG following intravenous injection of tyloxapol, the inhibitor of lipoprotein lipase preventing the metabolism, and removal of serum lipoprotein transporting TAG (VLDL and chylomicron). Notably, serum VLDL and VLDL-TAG levels were declined in mice fed with HFD for 12 weeks by around $35 \%$ and $25 \%$, respectively, compared to the chow diet-fed mice within $2 \mathrm{hr}$ after tyloxapol injection (Figures $1 \mathrm{~d}$ and $1 \mathrm{e}$ ). It is consistent with the previous studies showing attenuated VLDL secretion after HFD-feeding (Cahova et al., 2012; Francone et al., 1992; Oussadou et al., 1996; Yang et al., 2015). In the present investigation, HFD-induced increase in serum TAG should be due to the elevated chylomicron concentration, the lipoprotein mediating TAG absorption from food, since the secretion of Apo-48, the typical component in chylomicron, was increased after 12-week HFD-feeding (data not shown). Our data suggest that the decline of VLDL secretion may be an important driver in the development of hepatic seatosis.

\subsection{The expression of hepatic ApoB is reduced in hepatic steatosis}

Since HFD-feeding attenuated VLDL secretion, we hypothesize that it may result from the misregulation of $A p o B$, the key component of VLDL, or MTTP, the enzyme mediating the assembling, and secretion of VLDL. Although hepatic mRNA expression of MTTP was upregulated by HFD-feeding (Figure $2 \mathrm{a}$ ), the protein expression remains normal (Figure $2 b$, upper panel). However, both hepatic mRNA and protein levels of $A p o B-100$, the subtype of $A p o B$ synthesized in liver, were reduced under HFD-feeding (Figures $2 a$ and $2 b$, middle panel). Furthermore, HFD-fed mice had lower serum level of ApoB-100 (Figure 2c, upper panel), probably caused by less secretion of ApoB100 compared to those fed with normal chow. It is evidenced by the attenuated accumulation of serum ApoB-100 under the treatment of tyloxapol in HFD-fed mice (Figure 2c, lower panel). Together, these results suggest that HFD-reduced hepatic VLDL secretion is correlated to the inhibition of $A p o B$ expression in liver.

\subsection{HFD induces cytoplasmic retention of HNF4a in liver}

HNF4a is a master regulator for ApoB expression (Hayhurst et al., 2001; Yin et al., 2011), we reason that HFD leads to malfunction of HNF4a, which disturbs ApoB transcription. To this end, we examined the expression of hepatic HNF4a, and found that both mRNA and total protein levels of hepatic HNF4a of HFD-fed mice is comparable to 
(a)

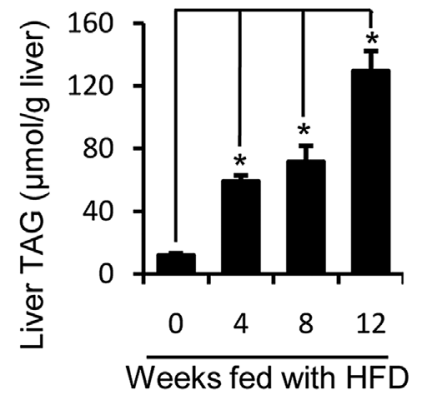

(b)

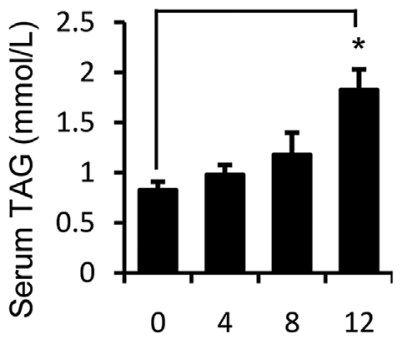

Weeks fed with HFD (c)

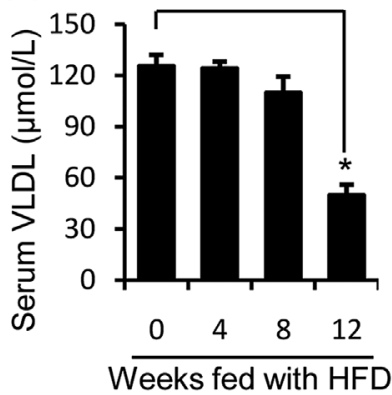

(d)

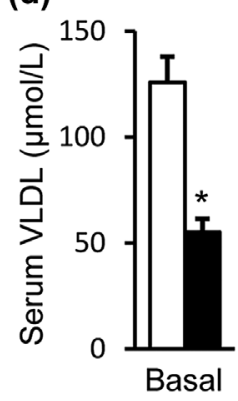

(e)

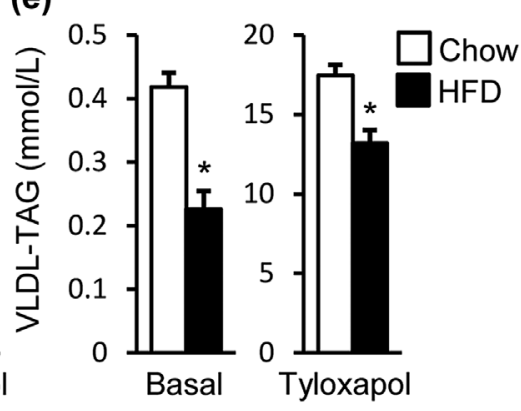

FIGURE 1 HFD induces hepatic TAG accumulation with reduction of VLDL secretion in mice. Mice, fed with HFD for 0, 4, 8, or 12 weeks until 20 weeks old, were executed in fed states ( $n=6$ per group). (a) Liver TAG assay; (b) serum TAG assay; (c) serum VLDL assay. (d and e) Mice, fed with normal chow or HFD for 12 weeks until 20 weeks old were administrated by tyloxapol $(600 \mathrm{mg} / \mathrm{kg})$ i.v.; serum was taken for VLDL assay (d) and VLDL-TAG assay (e). The data are expressed as the mean \pm S.E., ${ }^{*} p<0.05$

(a)

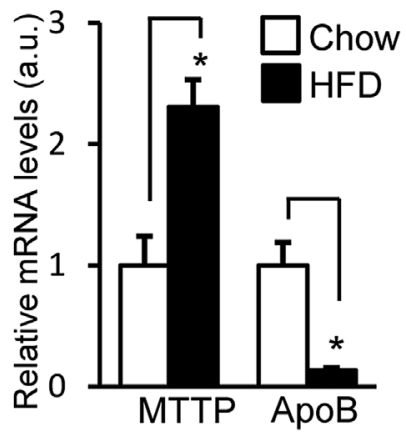

(b)

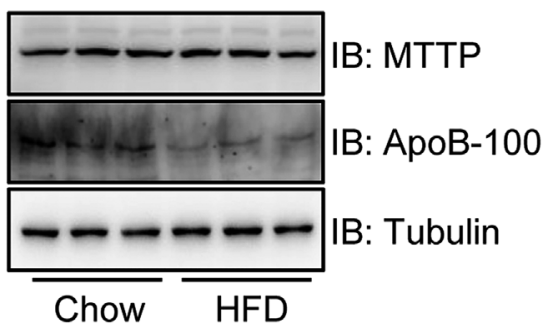

(c)
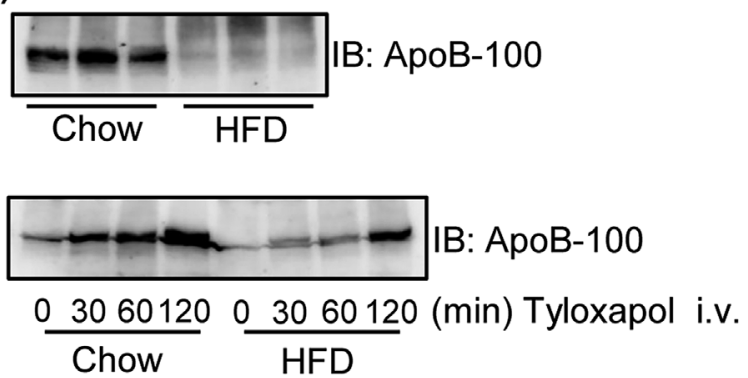

FIGURE 2 Hepatic ApoB expression is reduced in hepatic steatosis. Male mice were fed with normal chow or HFD for 12 weeks until 20 weeks old. (a) Total RNA was isolated from livers for mRNA level assay detected by RT-qPCR and normalized to 36B4 mRNA level. Data are expressed as fold-change relative to the level of chow-fed mice, $n=6$ per group. The data are expressed as the mean \pm S.E., ${ }^{*} p<0.05$. (b) Liver extracts were immunoblotted by antibodies against MTTP, ApoB-100 or tubulin. (c) Upper panel, serum isolated from three mice were individually immunoblotted by ApoB-100 antibody; lower panel, mixed serum isolated from three mice at different time point after the treatment of tyloxapol were immunoblotted by ApoB-100 antibody. a.u., arbitrary units 
(a)

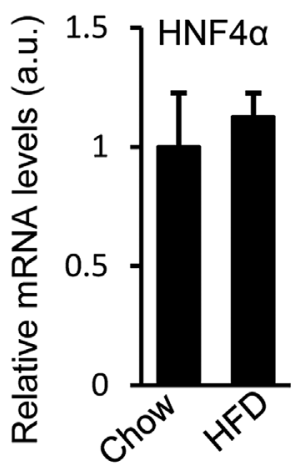

(b)

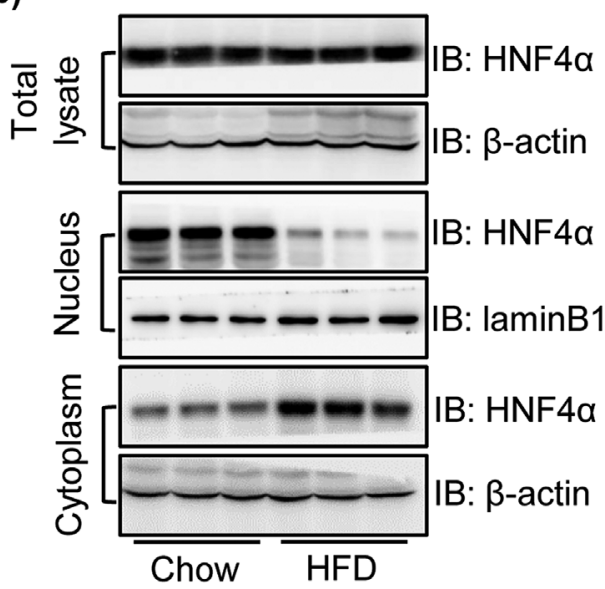

FIGURE 3 HFD induces cytoplasmic retention of HNF4a in liver. Male mice were fed with normal chow or HFD for 12 weeks until 20 weeks old. (a) Total RNA was isolated from livers to detect mRNA level of HNF4a by RT-qPCR and normalized to 36B4 mRNA level. Data are expressed as fold-change relative to the level of chow-fed mice, $n=6$ per group. The data are expressed as the mean \pm S.E., ${ }^{*} p<0.05$. (b) Proteins from nucleus, cytoplasm, and liver extracts were immunoblotted by antibodies of HNF4a, laminB1 or $\beta$-actin. a.u., arbitrary units

those fed with normal chow (Figures 3a and 3b, upper panel). However, further examination in nucleus/cytoplasm distribution of HNF4a revealed that HFD-feeding reduced HNF4a protein content in the nucleus, but increased its cytoplasmic content (Figure $3 b$, middle and lower panel), suggesting that the abnormal subcellular localization of $\mathrm{HNF} 4 a$ reduces the regulating capacity of $\mathrm{HNF} 4 a$ on $\mathrm{ApoB}$ expression.

\subsection{Oxidative stress-induced phosphorylation and cytoplasmic retention of HNF4a are regulated by PKCs in hepatocytes}

We have shown above that the HFD-feeding induced the cytoplasmic retention of HNF4a. To dissect which factor dominates the subcellular localization of HNF4a in hepatic steatosis, we treated primary hepatocytes with $\mathrm{H}_{2} \mathrm{O}_{2}$, PA, LPS, TNFa, insulin, and glucose to mimic hepatic internal milieu, such as oxidative stress, hyperlipidemia, inflammation, hyperinsulinemia, and hyperglycemia, the typical risk factors related to hepatic steatosis. It is noteworthy that only $\mathrm{H}_{2} \mathrm{O}_{2}$ treatment resulted in striking cytoplasmic retention of HNF4a in the hepatocytes (Figure 4a). To determine whether HFD-feeding leads to liver oxidative stress, we examined the hepatic levels of two oxidant markers, ROS, and MDA. As shown in Figures 4b and 4c, 12-week HFD feeding significantly increased the levels of liver ROS and MDA, which is consistent to the previous reports (Dutta et al., 2014; RincónCervera et al., 2016). Furthermore, we found that HFD reduced the activity and mRNA levels of some important antioxidant enzymes, SOD, and CAT (Figures 4d and 4e). NRF2, an essential regulator promoting the transcription of a broad range of antioxidant genes and usually activated by oxidative stress (Kensler, Wakabayashi, \& Biswal, 2007), was significantly increased in mRNA level (Figure 4e). All the data indicated that the oxidative stress affects throughout the development of NAFLD.
It had been reported that phosphorylation on Ser78 by PKC leads to the cytoplasmic localization of HNF4a (Sun et al., 2007) and acetylation of HNF4a by CREB-binding protein increased the HNF4a DNA binding and its transcriptional activity (Soutoglou, Katrakili, \& Talianidis, 2000). Thus, we examined the phosphorylation and acetylation status of HNF4a in the liver of HFD-induced obese mice. Interestingly, immunoprecipitation of HNF4a followed by immunoblot against either serine phosphorylation or lysine acetylation sites revealed that HFD-feeding increased the serine phosphorylation of HNF4a without affecting its acetylation in liver (Figure 5a). Given that $\mathrm{H}_{2} \mathrm{O}_{2}$ treatment activates PKC (Konishi et al., 1997; Lee et al., 2009), and HNF4a is a downstream substrate of PKC (Sun et al., 2007), we next test whether oxidative stress by $\mathrm{H}_{2} \mathrm{O}_{2}$ regulates serine phosphorylation of HNF4a. As shown in Figure 5b, $\mathrm{H}_{2} \mathrm{O}_{2}$ treatment increased the serine phosphorylation of HNF4a by $60 \%$ in hepatocytes, while the combination with Go6983 (denoted as Go), a PKC inhibitor, partially reversed the phosphorylation by $30 \%$. Correspondingly, $\mathrm{H}_{2} \mathrm{O}_{2}$ treatment increased cytoplasmic protein fraction of $\mathrm{HNF} 4 \alpha$ and decreased its nuclear protein content, while Go6983 partially reversed $\mathrm{H}_{2} \mathrm{O}_{2}$ mediated cytoplasmic retention of HNF4a (Figure 5c). Furthermore, immunofluorescence data also confirmed the $\mathrm{H}_{2} \mathrm{O}_{2}$-regulated nucleus/cytoplasm distribution of $\mathrm{HNF} 4 \mathrm{a}$ via PKC (Figure 5d).

\subsection{Oxidative stress inhibits HNF4a mediated transcription of ApoB and reduces VLDL and TAG secretion from primary hepatocytes}

Given that $\mathrm{H}_{2} \mathrm{O}_{2}$ promotes cytoplasmic retention of $\mathrm{HNF} 4 \mathrm{a}$, this urge us to test whether $\mathrm{H}_{2} \mathrm{O}_{2}$ affects transcriptional activity of HNF4a on its target gene. As expect, our reporter gene assay performed in HepG2 cells demonstrated that $\mathrm{H}_{2} \mathrm{O}_{2}$ treatment significantly inhibited the ApoB promoter-driven luciferase when co-transfecting HNF4a, 
(a)

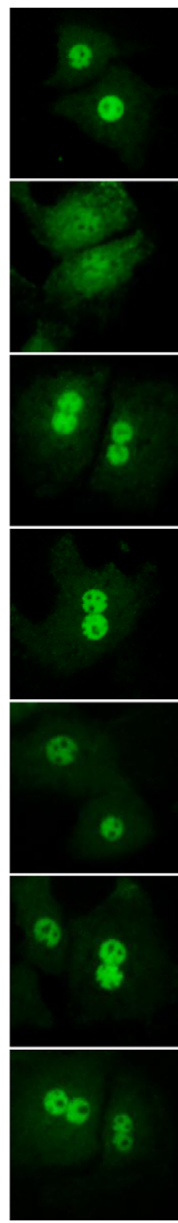

$\mathrm{HNF} 4 \alpha$

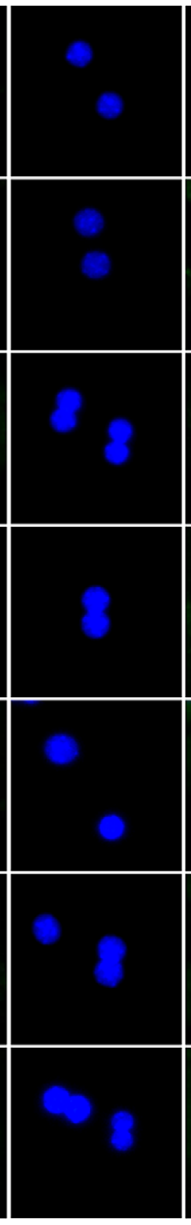

DAPI

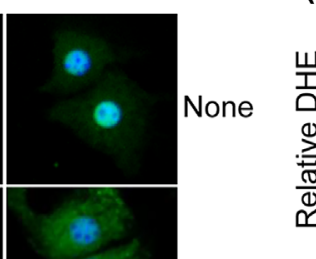

$\mathrm{H}_{2} \mathrm{O}_{2}$

(c)

(b)
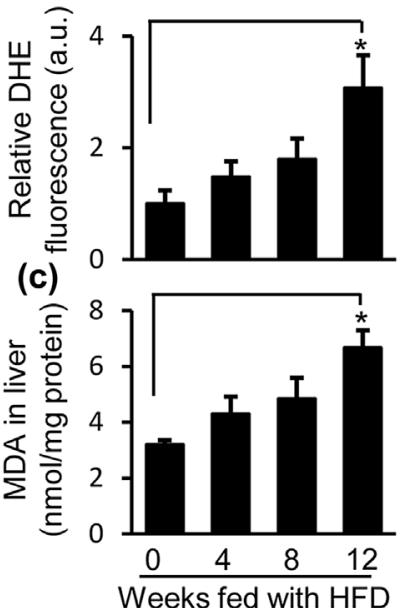

(d)
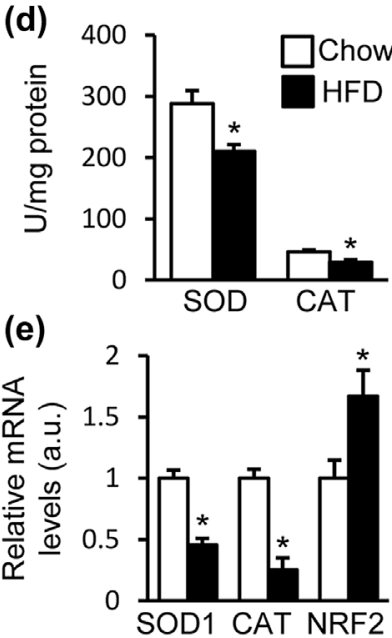

FIGURE 4 Oxidative stress induces the cytoplasmic retention of HNF4a in hepatocyte. (a) Primary hepatocytes were isolated and cultured in WME supplemented with $6 \% \mathrm{FBS}$ for $5 \mathrm{hr}$ and then grown in serum free medium plus stimuli, including $\mathrm{H}_{2} \mathrm{O}_{2}(1 \mu \mathrm{M})$, PA (250 $\left.\mu \mathrm{M}\right)$, LPS $(1 \mathrm{\mu g} / \mathrm{ml}), \mathrm{TNFa}(10 \mathrm{ng} / \mathrm{ml})$, insulin $(100 \mathrm{nM})$, glucose $(30 \mathrm{mM})$ for further $24 \mathrm{hr}$. Dexamethasone $(100 \mathrm{nM})$ was added $6 \mathrm{hr}$ before harvesting. Fixed cells were stained with HNF4a primary antibody and Alexa Fluor 488 goat anti-rabbit secondary antibody (Green), DAPI (blue) was incorporated in the mounting solution. (b-e) Mice fed with HFD for 0, 4, 8, or 12 weeks until 20 weeks old. ROS (b), MDA (c), SOD and CAT activity (d) in liver were assayed ( $n=6$ per group). (e) Hepatic mRNA levels of SOD1, CAT, and NRF2 were determined using RT-qPCR and normalized to 36B4 mRNA level. The data are expressed as the mean \pm S.E., ${ }^{*} p<0.05$ versus group without HFD-feeding. a.u., arbitrary units

while addition of $\mathrm{G} 06983$ eliminated the inhibitory effect of $\mathrm{H}_{2} \mathrm{O}_{2}$ (Figure 6a). In addition, the similar pattern was found in the regulation of endogenous mRNA level of $A p o B$ by $\mathrm{H}_{2} \mathrm{O}_{2}$ or plus $\mathrm{G} 06983$ treatment in primary hepatocytes (Figure 6b). Subsequently, whether the reduced transcriptional activity of $\mathrm{HNF} 4 \mathrm{a}$ by $\mathrm{H}_{2} \mathrm{O}_{2}$ treatment affects the VLDL secretion was tested. As expected, $\mathrm{H}_{2} \mathrm{O}_{2}$ treatment inhibited the secretion of VLDL and TAG from the primary hepatocytes, while Go6983 almost eliminated this effect (Figures $6 c$ and $6 d)$.

\section{6 | PKC $\delta$ and $\varepsilon$ phosphorylate HNF4a specifically at Ser78 and blocks HNF4a from transferring into nucleus}

PKC includes various isotypes, therefore it is necessary to make out which one mediates the phosphorylation and malfunction of HNF4a.
PKC $\delta$ and $\varepsilon$ were chosen to be tested, for they are over-activated in livers developing steatosis or by oxidative stress (Birkenfeld \& Shulman, 2014; Greene et al., 2010; Jung et al., 2004; Majumder et al., 2001). The luciferase assay indicated that both isotypes suppressed HNF4a-mediated transcription of ApoB (Figure 7a). Actually, we also tested the effect of PKC $\alpha, \beta$, and $\zeta$, and found that they were all inhibitory to HNF4a (data not shown), which implies that the inhibitory effect on HNF4a may be prevail among PKC isotypes.

Utilizing in vitro kinase assay, Sun et al. (2007) revealed that PKC phosphorylated HNF4a at multiple sites at least including Ser78 and Ser304. But this in vitro zymological method could not precisely demonstrate the physiologic interaction between PKC and HNF4a in cell. In the present study, we expressed the WT HNF4a or S78A (the Ser78-nonphophorylated HNF4a mutant) with PKCD in COS-7 cells (the cell line with low endogenous HNF4a expression, Supplemental 
(a)

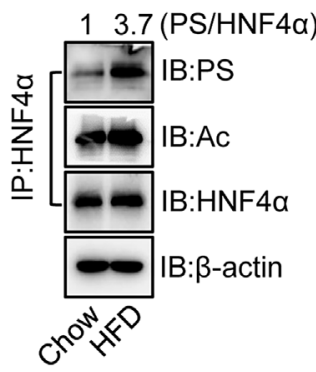

(c)

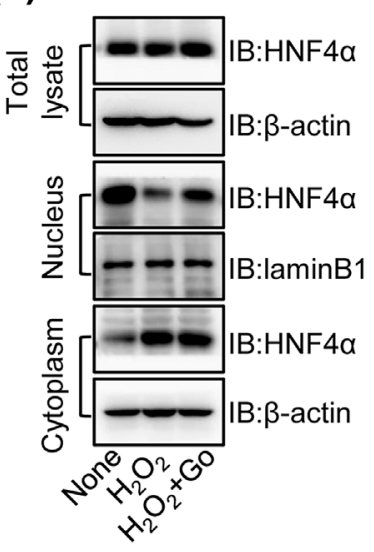

(b)

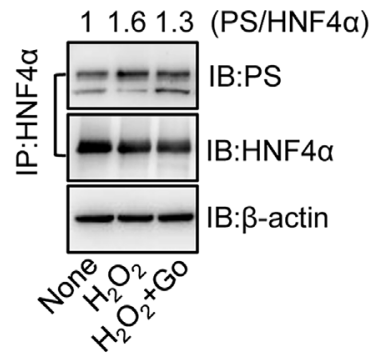

(d)

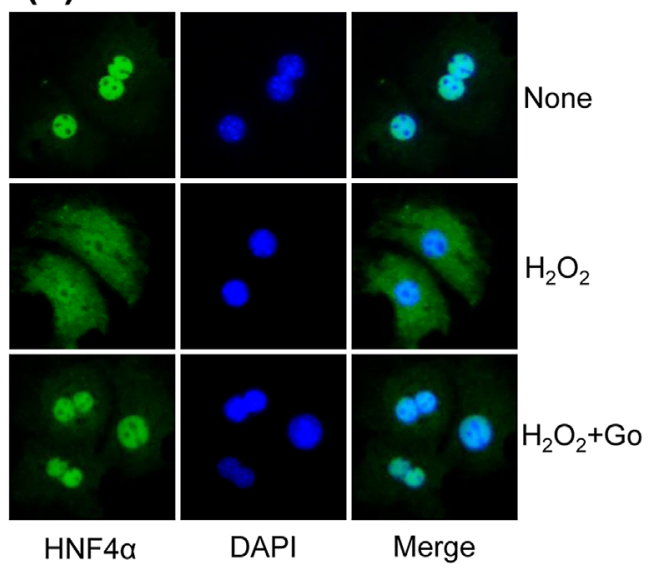

FIGURE 5 Oxidative stress induces the cytoplasmic retention of HNF4a via PKC mediated phosphorylation on HNF4a. (a) Extracts, from livers of mice fed with normal chow or HFD for 12 weeks, were immunoprecipitated by anti-HNF4a antibody; the blots were immunoblotted by antibody against phospho-serine (denoted as PS), acetylated-lysine (denoted as Ac), or HNF4a. $\beta$-actin in extracts was immunoblotted as input. (b-d) Primary hepatocytes were cultured in WME supplemented with $6 \%$ FBS for $5 \mathrm{hr}$ and then grown in serum-free medium with/ without $\mathrm{H}_{2} \mathrm{O}_{2}(1 \mu \mathrm{M})$ or plus Go6983 (1 $\mu \mathrm{M}$, denoted as Go) for further $24 \mathrm{hr}$. Dexamethasone (100 nM) was added $6 \mathrm{hr}$ before harvesting. (b) Hepatocyte extracts were immunoprecipitated by HNF4a antibody; the blots were immunoblotted by phospho-serine (PS) and HNF4a antibody. $\beta$-actin in extracts was immunoblotted as input. Bands were quantified from immunoblot digital images using ImageJ software. Relative intensity of phospho-serine bands was normalized by that of HNF4a bands, and results are presented above the immunoblot image. (c) Proteins from hepatocyte extracts, nucleus and cytoplasm were immunoblotted by antibody of HNF4a, laminB1 or $\beta$-actin. (d) Fixed cells were stained with HNF4a antibody and Alexa Fluor 488 goat anti-rabbit secondary antibody (Green), DAPI (blue) was incorporated in the mounting solution

Figure S1A). Via immunoprecipitation-immunoblotting, we found that PKC $\delta$ enhanced serine phosphorylation of WT HNF4a by $50 \%$, but no similar enhancement in phosphorylation of S78A was observed (Figure 7b), implying that, in the physiologic state, PKC $\delta$ mainly acts on Ser78 of HNF4a at cellular level. Interestingly, S78A got higher basal level in serine-phosphorylation than WT HNF4a. We reason that Ser78 affects the phosphorylation of other serine residues in HNF4a, which need to be further explored.

Previous study reported that the protein nuclear exporting system had no effect on the subcellular localization of HNF4a (Sun et al., 2007). In the present study, we focus on the protein nuclear importing mediator, importin. Its inhibitor, importazole, was used to treat COS-7 cells transfected with the expressing vectors of WT HNF4a, S78A, and S78D (the constitutively Ser78-phophorylated HNF4a mutant). MG132 was utilized to prevent the potential proteasome-induced protein degradation. The Figure 7c showed that WT and S78A could be transported into nucleas and their nuclear transportation was inhibited by importazole. S78D was dominantly localized in cytoplasm and not affected by importazole.
This result infers that the nuclear transportation of HNF4a relays on importin, but, once phosphorylated at Ser78, HNF4a is not transportable and thus retains in the cytoplasm.

\section{4 | DISCUSSION}

Hepatic VLDL secretion is the main pathway to transport the TAG from liver to peripheral tissues and also an important contributor to the hepatic lipid homeostasis (Cohen et al., 2011). Disruption of VLDL secretion would generate severe hepatic steatosis, for instance, in hepatitis C virus infected patients (Gupte, Dudhade, \& Desai, 2006), who got acquired deficiency in ApoB, a key component of VLDL (Gruffat, Durand, Graulet, \& Bauchart, 1996). Interestingly, the malfunction of VLDL secretion also occurs in HFD-induced NAFLD (Cahova et al., 2012; Francone et al., 1992; Kalopissis, Griglio, Malewiak, \& Rozen, 1980; Oussadou et al., 1996; Yang et al., 2015), and the underlying mechanism is rather complicated. The present investigation reveals that HFD-induced oxidative stress prevents the 
(a)

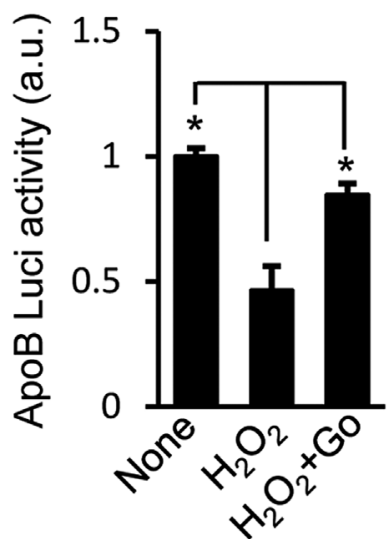

(c)

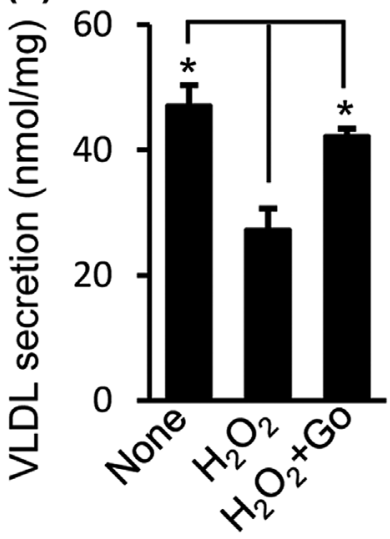

(b)

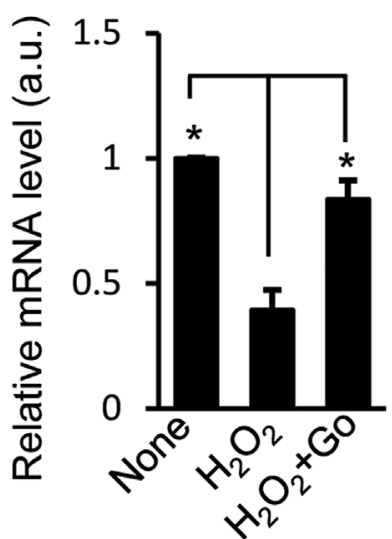

(d)

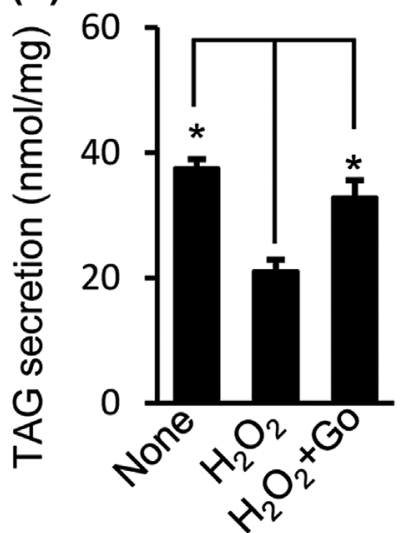

FIGURE 6 Oxidative stress inhibits VLDL secretion by reducing ApoB transcription in hepatocytes. (a) HNF4a expression vectors (50 ng), and pGL3-ApoB (ApoB promoter driven luciferase) construct ( $200 \mathrm{ng}$ ) plus pRL-TK-Renilla (10 ng) were co-transducted into HepG2 cells. Thirty-six hours later, cells were serum starved and treated with or without $\mathrm{H}_{2} \mathrm{O}_{2}(1 \mu \mathrm{M})$ or plus Go6983 (1 $\mu \mathrm{M}$, denoted as Go) for further $24 \mathrm{hr}$ culture. Luciferase (Luci) activity was normalized by Renilla luciferase values. Data are expressed as fold-change relative to the level of control. (b-d) Primary hepatocytes were cultured in WME supplemented with $6 \%$ FBS for $5 \mathrm{hr}$ and then grown in serum free medium with dexamethasone $(100 \mathrm{nM})$ for further $24 \mathrm{hr} . \mathrm{H}_{2} \mathrm{O}_{2}(1 \mu \mathrm{M})$ or plus Go6983 $(1 \mu \mathrm{M})$ was added at the same time. (b) Total RNA was isolated from hepatocytes to detect mRNA level of HNF4a by RT-qPCR and normalized to 36B4 mRNA level. (c and d) After 24-hr culture in serum-free WME, medium was switched to serum free, phenol free DMEM with $11 \mathrm{mM}$ glucose for further 24-hr culture. $\mathrm{H}_{2} \mathrm{O}_{2}(1 \mu \mathrm{M})$ or plus Go6983 $(1 \mu \mathrm{M})$ was added at the same time. Then, supernatants were used for VLDL (c) and TAG (d) secretion assay. All these data were normalized by cell protein levels. Data were presented as mean \pm S.E., ${ }^{*} p<0.05$. a.u., arbitrary units

nuclear translocation of HNF4a due to PKC-mediated phosphorylation, and thus reduced the transcription of $A p o B$, the downstream of HNF4a, as well as the subsequent VLDL secretion.

The NAFLD model was replicated in C57BL/6 mice by HFD-feeding, and showed similar reduction in hepatic VLDL secretion as in previous studies (Figure 1). Hepatic VLDL secretion depends on ApoB, the key component of VLDL, and MTTP, the enzyme mediating the assembling and secretion of VLDL. The down-regulation in mRNA and protein levels of hepatic $A p o B$ should induce the disruption of VLDL secretion in HFD-fed mice, in terms of no change found in MTTP protein level (Figure 2).

ApoB expression is regulated by several transcriptional factors, including HNF4a, C/EBPa, and PPARa (Hayhurst et al., 2001; Nóvak, Dantas, Charbel, \& Bydlowski, 1998; Yin et al., 2011), of which HNF4a may dominate this regulatory process. First, previous data indicated that the level of $A p o B$ was closely related to the expression of HNF4a in liver, that is, the adenovirus vector-delivered over-expression of HNF4a in liver enhanced the expression of hepatic ApoB (Yin et al., 2011), and the liver-specific knockout of HNF4a or short hairpin RNA-induced knockdown of HNF4a reduced ApoB expression (Hayhurst et al., 2001; Yin et al., 2011). Moreover, HNF4a is required in the promotion of $A p o B$ transcription via C/EBPa, that is, HNF4a binding to DNA induces a DNA helix bend, thus facilitating the communication with a C/EBPa located one helix turn from this HNF4a in the ApoB promoter (Nóvak et al., 1998). Finally, PPARa just functions as a guard against the overexpression of $A p o B$ but would not reduce the hepatic $A p o B$ transcription, for PPARa deficiency increases but PPARa overactivation fails to reduce hepatic ApoB mRNA level (Linden et al., 2002; Su et al., 2014).

Strikingly, we observed the HFD-induced abnormal cytoplasmic retention of HNF4a (Figure $3 \mathrm{~b}$ ) with normal mRNA and protein levels (Figure 3), instead of reduction in mRNA and protein levels of 
(a)

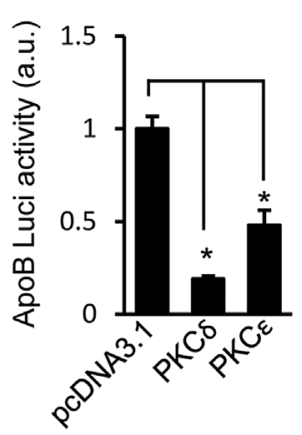

(b)

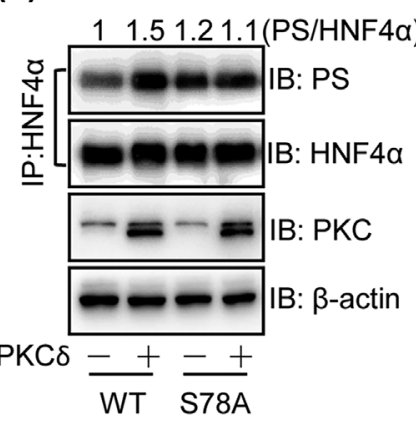

(c)

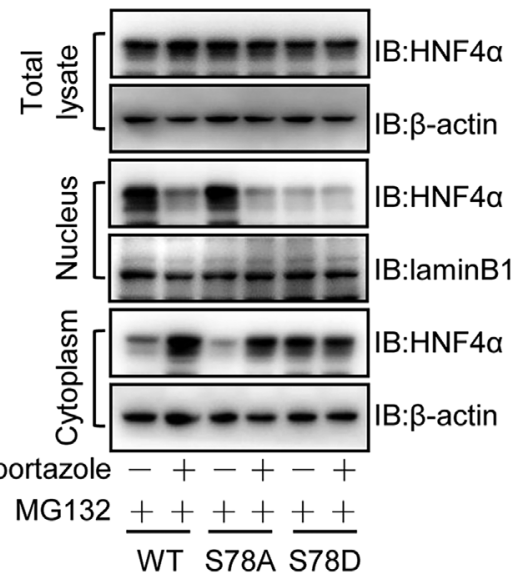

FIGURE 7 PKC $\delta$ and $\varepsilon$ phophorylate HNF4a specifically at Ser78 and inhibits the translocation of HNF4a into nucleus. (a) The expression vectors of PKC isotypes (100 ng) were co-transfected with HNF4a (50 ng), pGL3-ApoB construct (200 ng), and pRL-TK-Renilla (10 ng) into HepG2 cells. Thirty-six hours later, cells were harvested for luciferase activity assay. Data represent average of three biological replicates assayed in technical triplicates and are presented as mean \pm S.E., ${ }^{*} p<0.05$. a.u., arbitrary units. (b) COS-7 cells were transfected with expressing vectors of WT HNF4a or S78A mutant with PKC $8.48 \mathrm{hr}$ later, cells were harvested and cell extracts were immunoprecipitated by HNF4 $\alpha$ antibody; the blots were immunoblotted by phospho-serine (PS) and HNF4a antibody. $\beta$-actin (as input) and PKC $\delta$ in extracts was immunoblotted. Bands were quantified from immunoblot digital images using Image $J$ software. Relative intensity of phospho-serine bands was normalized by that of HNF4a bands, and results are presented above the immunoblot image. (c) COS-7 cells were transfected with expressing vectors of WT HNF4a, S78A and S78D mutants. Twelve hours later, cells were treated by importazole (40 $\mu$ M) and MG132 $(50 \mu \mathrm{M})$ for another $12 \mathrm{hr}$. Proteins from nucleus, cytoplasm, and total cell extracts were immunoblotted by antibodies of HNF4a, laminB1 or $\beta$-actin

hepatic HNF4a after HFD feeding, as reported by Yang et al (2015), although both ways could block the transcriptional function of HNF4a, and consequently result in the attenuated expression of ApoB. The different phenotypes were possibly caused by the different HFD-feeding duration, since HFD with similar nutritional composition was fed for 12 weeks in present study and 16 weeks in the previous one. It implies that before the reduction in expression level, hepatic HNF4a already got functional impairment in the early stage of HFD-feeding.

However, the protein level of MTTP, another target gene of HNF4a, did not manifest reduction in HFD-fed mice (Figure 2b). Probably, other regulators of MTTP, PPARa, (Améen et al., 2005) and Foxo1 (Kamagate et al., 2008), with increased transcriptional activity in hepatic steatosis (Sambasiva Rao \& Reddy, 2004; Valenti et al., 2008), would up-regulate MTTP transcription, suggesting that PPARa, and Foxo1 may exert compensatory effects on MTTP expression under the malfunction of HNF4a.

To explore the subcellular misallocation of HNF4a in hepatocytes, we screened potential factors affecting HNF4a localization in cellular level, and found that $\mathrm{H}_{2} \mathrm{O}_{2}$ (imitating oxidative stress) rather than other treatments, induced the cytoplasmic retention of HNF4a (Figure 4a). Consistently, $\mathrm{H}_{2} \mathrm{O}_{2}$ blocks HNF4a mediated ApoB transcription in HepG2 cells and primary hepatocytes, evidenced by the decrease in ApoB promoter driven luciferase, endogenous ApoB mRNA level, and hepatic secretion of VLDL and TAG (Figure 6). In agree with those ex vivo results, in vivo data indicated that HFD-fed mice suffered from oxidative stress in liver, evidenced by the elevated hepatic ROS, and MDA levels (Figures b and 4c), as well as the abnormality in activity or
mRNA levels of antioxidative genes, including SOD, CAT, and NRF-2 (Figures 4d and 4e). Notably, it is reported that HNF4a promotes the anti-oxidative capacity of cells via stimulating NRF-2 to transcribe its downstream anti-oxidative genes, such as SOD, and CAT (Marcil et al., 2010). We reason that oxidative stress inhibiting HNF4a activity would enhance itself via impairing HNF4a/NRF-2/anti-oxidative genes pathway. However, this hypothesis needs to be tested in additional study.

Another NAFLD model, leptin-deficient mice (ob/ob) confirmed that oxidative stress rather than hepatic steatosis that directly induces the misallocation and malfunction of HNF4a, since no significant reduction in nuclear HNF4a protein level or ApoB mRNA level occurred in liver of ob/ob mice (Supplemental Figure S2A and S2B), who got relatively normal hepatic ROS and MDA levels (Supplemental Figures S2C). Therefore, oxidative stress is likely the main cause inhibiting transcriptional activity of HNF4a, which subsequently results in the lower ApoB expression, decreased secretion of VLDL, and eventually develops NAFLD. "Multiple hit" hypothesis considers that oxidative stress evoked by mitochondrial dysfunction under overaccumulation of lipids in liver plays an important role in NASH pathogenesis (Sumida, Niki, Naito, \& Yoshikawa, 2013; Takaki, Kawai, $\&$ Yamamoto, 2013). However, our data suggest that oxidative stress may also aggravate the hepatic steatosis, therefore the anti-oxidative therapy, such as activation of antioxidant system, is a feasible way to prevent hepatic steatosis, and NASH (Okada et al., 2012; Wheeler et al., 2001).

The mechanism how $\mathrm{H}_{2} \mathrm{O}_{2}$ modulates $\mathrm{HNF} 4 \mathrm{a}$ was investigated next. It is interesting to note that phosphorylation on Ser78 by PKC 
leads to cytoplasmic localization of HNF4a (Sun et al., 2007). Thus, we presume that PKC could mediate $\mathrm{H}_{2} \mathrm{O}_{2}$-induced HNF4a misallocation since $\mathrm{H}_{2} \mathrm{O}_{2}$ is a PKC activator (Konishi et al., 1997; Lee et al., 2009). Indeed, $\mathrm{H}_{2} \mathrm{O}_{2}$ treatment promoted the serine phosphorylation of HNF4a in hepatocytes, which could be reversed by a specific PKC inhibitor, Go6983 (Figure 5b). Besides, Go6983 also prevent the $\mathrm{H}_{2} \mathrm{O}_{2-}$ induced $\mathrm{HNF} 4 \mathrm{a}$ misallocation (Figures $5 \mathrm{c}$ and $5 \mathrm{~d}$ ) as well as reduction in ApoB transcription (Figure 6). Consistent with the ex vivo data, the serine phosphorylation level of HNF4a was significantly enhanced by HFD (Figure 5a) under the elevated hepatic oxidative stress (Figures $4 \mathrm{~b}$ and $4 \mathrm{c}$ ). Therefore, the misregulation of HNF4a cellular localization by $\mathrm{H}_{2} \mathrm{O}_{2}$ is through PKC-mediated serine phosphorylation of $\mathrm{HNF} 4 \mathrm{a}$ (Figures 5-6). It is a pity that we are lack of specific antibody against phospho-HNF4a (Ser78) currently to directly value the phosphorylation level of Ser78 in HNF4a, which is still under preparation. But the failure to enhance serine-phosphorylation level of HNF4a mutant (S78A) by PKC (Figure 7b) confirms that Ser78 is the primary site acted on by PKC, and thus total serine-phosphorylation level could generally reflect the phosphorylation level of Ser78 in HNF4a.

PKC has various isotypes, but only PKC 8 and $P K C \varepsilon$ are overactivated in livers when steatosis develops or by oxidative stress (Birkenfeld \& Shulman, 2014; Greene et al., 2010; Jung et al., 2004; Majumder et al., 2001). The luciferase assay indicated that these two PKC isotypes inhibited the transcriptional activity of HNF4a on ApoB expression (Figure 7a), implying that $\mathrm{PKC} \delta$ and $P K C \varepsilon$ are likely responsible for the malfunction of hepatic HNF4a in HFD-fed mice. The specific phosphorylation sites in HNF4a recognized by PKC had been studied by Sun et al. (2007), but their ex vivo zymological method was defective to precisely reflect the physiologic protein-interaction in alive cells. Thus, we tested the protein modification of HNF4a by PKCs at the cellular level, and found that Ser78 was the primary site acted on by PKC, since the phosphorylation level of S78A mutants could not be enhanced by co-transfected PKC (Figure 7b). Ser78 is functional in HNF4a subcellular localization. Previous study reported that the

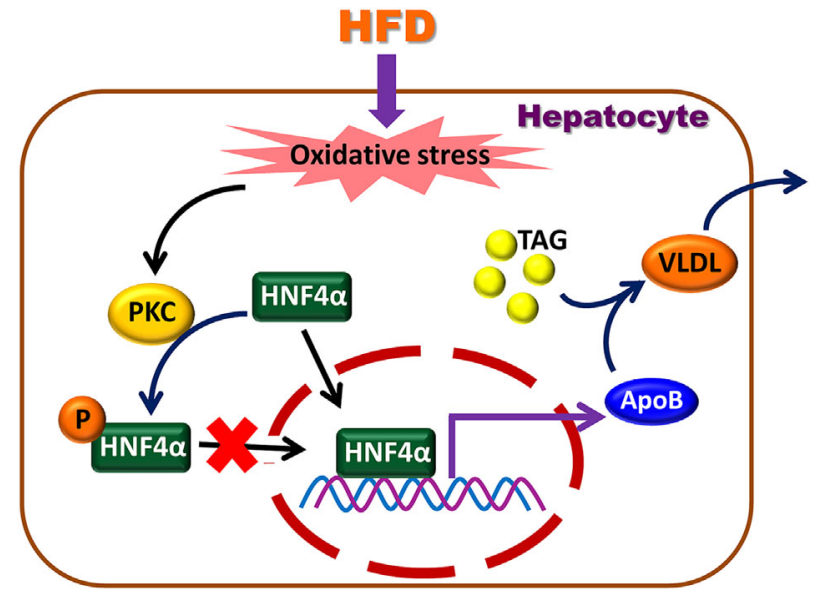

FIGURE 8 A scheme demonstrating the function of HFD-evoked oxidative stress in hepatocytes, modulation of the transcriptional activity of HNF4a, impairment of VLDL secretion, and contribute in the development of hepatic steatosis protein nuclear exporting system had no effect on the subcellular localization of HNF4a (Sun et al., 2007). Thus, the present study focuses on the role of the protein nuclear importing mediator, importin. Results in Figure 7c suggest that once phosphorylated on Ser78, the HNF4a could not transfer into nucleus via importin, and thus retains in the cytoplasm. While, the nonphosphorylated HNF4a is susceptible to importin and mostly localizes in nucleus. Therefore, the high Ser78 phosphorylation rate reduces the nuclear transportation of HNF4a and subsequently suppresses its transcriptional activity.

In summary, our study confirms that the hepatic oxidative stress provoked by HFD induces cytoplasmic retention of HNF4a in hepatocytes is mediated by the activation of PKC. For the first time, we find that HNF4a is prevented from transferring into nucleus once phosphorylated at Ser78 by PKC, which consequently blocks transcription of $A p o B$, decreases the hepatic secretion of VLDL and promotes hepatic TAG accumulation (Figure 8). Thus, oxidative stress/PKC/HNF4a/ApoB pathway may be a novel target to treat HFD-induced fatty liver.

\section{ACKNOWLEDGMENTS}

This work was supported in whole or part by Natural Science Foundation of China (81400613) and Natural Science Foundation of Jiangsu Province China (BK20140901 and BK2015041792). We thank Prof. Liangyou Rui for the gift of pcDNA3.0-HNF4a. We also acknowledge Dr. Dongping Wei for the gift of pGL3-ApoB.

\section{CONFLICTS OF INTEREST}

The authors declare that they have no conflicts of interest with the contents of this article.

\section{ORCID}

Liang Sheng (iD http://orcid.org/0000-0003-1217-0392

\section{REFERENCES}

Alder, O., Cullum, R., Lee, S., Kan, A. C., Wei, W., Yi, Y., ... Morrissy, A. S. (2014). Hippo signaling influences HNF4A and FOXA2 enhancer switching during hepatocyte differentiation. Cell Reports, 9(1), 261-271.

Améen, C., Edvardsson, U., Ljungberg, A., Asp, L., Åkerblad, P., Tuneld, A., . . Oscarsson, J. (2005). Activation of peroxisome proliferator-activated receptor $a$ increases the expression and activity of microsomal triglyceride transfer protein in the liver. Journal of Biological Chemistry, 280(2), 1224-1229.

Berriot-Varoqueaux, N., Aggerbeck, L., Samson-Bouma, M.-E., \& Wetterau, J. (2000). The role of the microsomal triglygeride transfer protein in abetalipoproteinemia. Annual Review of Nutrition, 20(1), 663-697.

Birkenfeld, A. L., \& Shulman, G. I. (2014). Nonalcoholic fatty liver disease, hepatic insulin resistance, and type 2 diabetes. Hepatology, 59(2), 713-723.

Bonzo, J. A., Ferry, C. H., Matsubara, T., Kim, J.-H., \& Gonzalez, F. J. (2012). Suppression of hepatocyte proliferation by hepatocyte nuclear factor $4 a$ in adult mice. Journal of Biological Chemistry, 287(10), 7345-7356. 
Browning, J. D., \& Horton, J. D. (2004). Molecular mediators of hepatic steatosis and liver injury. The Journal of Clinical Investigation, 114(2), 147-152.

Cahova, M., Dankova, H., Palenickova, E., Papackova, Z., \& Kazdova, L. (2012). The opposite effects of high-sucrose and high-fat diet on fatty acid oxidation and very low density lipoprotein secretion in rat model of metabolic syndrome. Journal of Nutrition and Metabolism, 2012.

Cohen, J. C., Horton, J. D., \& Hobbs, H. H. (2011). Human fatty liver disease: Old questions and new insights. Science, 332(6037), 1519-1523.

Demacker, P., Hijmans, A., Brenninkmeijer, B., Jansen, A., \& Van't Laar, A. (1984). Five methods for determining low-density lipoprotein cholesterol compared. Clinical Chemistry, 30(11), 1797-1800.

Demacker, P. N., Hessels, M., Toenhake-Dijkstra, H., \& Baadenhuijsen, H. (1997). Precipitation methods for high-density lipoprotein cholesterol measurement compared, and final evaluation under routine operating conditions of a method with a low sample-to-reagent ratio. Clinical Chemistry, 43(4), 663-668.

Dutta, M., Ghosh, D., Ghosh, A. K., Bose, G., Chattopadhyay, A., Rudra, S., ... Mallick, S. (2014). High fat diet aggravates arsenic induced oxidative stress in rat heart and liver. Food \& Chemical Toxicology An International Journal Published for the British Industrial Biological Research Association, 66(4), 262-277.

Francone, O. L., Griffaton, G., \& Kalopissis, A.-D. (1992). Effect of a high-fat diet on the incorporation of stored triacylglycerol into hepatic VLDL. American Journal of Physiology-Endocrinology and Metabolism, 263(4), E615-E623.

Gaggini, M., Morelli, M., Buzzigoli, E., DeFronzo, R. A., Bugianesi, E., \& Gastaldelli, A. (2013). Non-alcoholic fatty liver disease (NAFLD) and its connection with insulin resistance, dyslipidemia, atherosclerosis and coronary heart disease. Nutrients, 5(5), 1544-1560.

Greene, M. W., Burrington, C. M., Ruhoff, M. S., Johnson, A. K., Chongkrairatanakul, T., ... Kangwanpornsiri, A. (2010). Pkc $\delta$ is activated in a dietary model of steatohepatitis and regulates endoplasmic reticulum stress and cell death. Journal of Biological Chemistry, 285(53), 42115.

Gruffat, D., Durand, D., Graulet, B., \& Bauchart, D. (1996). Regulation of VLDL synthesis and secretion in the liver. Reproduction Nutrition Development, 36(4), 375-389.

Gupte, P., Dudhade, A., \& Desai, H. (2006). Acquired apolipoprotein B deficiency with chronic hepatitis $C$ virus infection. Indian Journal of Gastroenterology, 25(6), 311.

Hayhurst, G. P., Lee, Y.-H., Lambert, G., Ward, J. M., \& Gonzalez, F. J. (2001). Hepatocyte nuclear factor $4 a$ (nuclear receptor 2A1) is essential for maintenance of hepatic gene expression and lipid homeostasis. Molecular and Cellular Biology, 21(4), 1393-1403.

Jung, Y. S., Bo, R. R., Bo, K. L., Mook-Jung, I., Kim, S. U., Lee, S. H., .. Moon, C. H. (2004). Role for PKC- $\varepsilon$ in neuronal death induced by oxidative stress. Biochemical \& Biophysical Research Communications, 320(3), 789-794.

Kalopissis, A.-D., Griglio, S., Malewiak, M.-I., \& Rozen, R. (1980). Effect of a high-fat diet on rat very low density lipo-protein secretion. Biochimica et Biophysica Acta (BBA)-Lipids and Lipid Metabolism, 620(1), 111-119.

Kalyanaraman, B., Darley-Usmar, V., Davies, K. J., Dennery, P. A., Forman, H. J., Grisham, M. B., ... Ischiropoulos, H. (2012). Measuring reactive oxygen and nitrogen species with fluorescent probes: Challenges and limitations. Free Radical Biology and Medicine, 52(1), 1-6.

Kamagate, A., Qu, S., Perdomo, G., Su, D., Kim, D. H., Slusher, S., ... Dong, H. H. (2008). FoxO1 mediates insulin-dependent regulation of hepatic VLDL production in mice. The Journal of Clinical Investigation, 118(6), 2347-2364.

Kensler, T. W., Wakabayashi, N., \& Biswal, S. (2007). Cell Survival Responses to Environmental Stresses Via the Keap1-Nrf2-ARE Pathway. Annual Review of Pharmacology \& Toxicology, 47(1), 89.

Konishi, H., Tanaka, M., Takemura, Y., Matsuzaki, H., Ono, Y., Kikkawa, U., ... Nishizuka, Y. (1997). Activation of protein kinase C by tyrosine phosphorylation in response to $\mathrm{H} 2 \mathrm{O} 2$. Proceedings of the National Academy of Sciences, 94(21), 11233-11237.

Lee, S. H., Na, S. I., Heo, J. S., Kim, M. H., Kim, Y. H., Lee, M. Y., ... Han, H. J. (2009). Arachidonic acid release by $\mathrm{H} 2 \mathrm{O} 2$ mediated proliferation of mouse embryonic stem cells: Involvement of $\mathrm{Ca} 2+/ \mathrm{PKC}$ and MAPKsinduced EGFR transactivation. Journal of Cellular Biochemistry, 106(5), 787-797.

Linden, D., Lindberg, K., Oscarsson, J., Claesson, C., Asp, L., Li, L., ... Olofsson, S. O. (2002). Influence of peroxisome proliferator-activated receptor alpha agonists on the intracellular turnover and secretion of apolipoprotein (Apo) B-100 and ApoB-48. The Journal of Biological Chemistry, 277(25), 23044-23053.

Loomba, R., \& Sanyal, A. J. (2013). The global NAFLD epidemic. Nature Reviews Gastroenterology and Hepatology, 10(11), 686-690.

Lv, H., Liu, Q., Zhou, J., Tan, G., Deng, X., ... Ci, X. (2017). Daphnetinmediated Nrf2 antioxidant signaling pathways ameliorate tert-butyl hydroperoxide ( $\mathrm{t}-\mathrm{BHP}$ )-induced mitochondrial dysfunction and cell death. Free Radical Biology and Medicine, 106, 38-52.

Majumder, P. K., Mishra, N. C., Sun, X., Bharti, A., Kharbanda, S., Saxena, S., ... Kufe, D. (2001). Targeting of protein kinase $C$ delta to mitochondria in the oxidative stress response. Cell Growth \& Differentiation the Molecular Biology Journal of the American Association for Cancer Research, 12(9), 465.

Marcil, V., Seidman, E., Sinnett, D., Boudreau, F., Gendron, F. P., Beaulieu, J. F., ... Levy, E. (2010). Modification in oxidative stress, inflammation, and lipoprotein assembly in response to hepatocyte nuclear factor 4alpha knockdown in intestinal epithelial cells. The Journal of Biological Chemistry, 285(52), 40448-40460.

Martinez-Jimenez, C. P., Kyrmizi, I., Cardot, P., Gonzalez, F. J., \& Talianidis, I. (2010). Hepatocyte nuclear factor $4 a$ coordinates a transcription factor network regulating hepatic fatty acid metabolism. Molecular and Cellular Biology, 30(3), 565-577.

Michelotti, G. A., Machado, M. V., \& Diehl, A. M. (2013). NAFLD, NASH and liver cancer. Nature Reviews Gastroenterology and Hepatology, 10(11), 656-665.

Nóvak, E. M., Dantas, K. C., Charbel, C. E., \& Bydlowski, S. P. (1998). Association of hepatic nuclear factor-4 in the apolipoprotein B promoter: A preliminary report. Brazilian Journal of Medical and Biological Research, 31(11), 1405.

Odom, D. T., Zizlsperger, N., Gordon, D. B., Bell, G. W., Rinaldi, N. J., Murray, H. L., .. G Gifford, D. K. (2004). Control of pancreas and liver gene expression by HNF transcription factors. Science, 303(5662), 1378-1381.

Okada, K., Warabi, E., Sugimoto, H., Horie, M., Tokushige, K., Ueda, T., ... Itoh, K. (2012). Nrf2 inhibits hepatic iron accumulation and counteracts oxidative stress-induced liver injury in nutritional steatohepatitis. Journal of Gastroenterology, 47(8), 924-935.

Oussadou, L., Griffaton, G., \& Kalopissis, A. (1996). Hepatic VLDL secretion of genetically obese Zucker rats is inhibited by a high-fat diet. American Journal of Physiology-Endocrinology and Metabolism, 271(6), E952-E964.

Perlemuter, G., Sabile, A., Letteron, P., Vona, G., Topilco, A., Chretien, Y., .. . Brechot, C. (2002). Hepatitis C virus core protein inhibits microsomal triglyceride transfer protein activity and very low density lipoprotein secretion: A model of viral-related steatosis. FASEB Journal, 16(2), 185-194.

Rincón-Cervera, M. A., Valenzuela, R., Hernandez-Rodas, M. C., Marambio, M., Espinosa, A., Mayer, S., ... Videla, L. A. (2016). Supplementation with antioxidant-rich extra virgin olive oil prevents hepatic oxidative stress and reduction of desaturation capacity in mice fed a high-fat diet: Effects on fatty acid composition in liver and extrahepatic tissues. Nutrition, 32(11-12), 1254-1267.

Sambasiva Rao, M., \& Reddy, J. K. (2004). PPARa in the pathogenesis of fatty liver disease. Hepatology, 40(4), 783-786.

Sheng, L., Zhou, Y., Chen, Z., Ren, D., Cho, K. W., Jiang, L., .. Rui, L. (2012). NF-[kappa] B-inducing kinase (NIK) promotes hyperglycemia and 
glucose intolerance in obesity by augmenting glucagon action. Nature Medicine, 18(6), 943-949.

Soutoglou, E., Katrakili, N., \& Talianidis, I. (2000). Acetylation regulates transcription factor activity at multiple levels. Molecular Cell, 5(4), 745-751.

Su, Q., Baker, C., Christian, P., Naples, M., Tong, X., Zhang, K., ... Adeli, K. (2014). Hepatic mitochondrial and ER stress induced by defective PPARa signaling in the pathogenesis of hepatic steatosis. American Journal of Physiology Endocrinology \& Metabolism, 306(11), E1264.

Sumida, Y., Niki, E., Naito, Y., \& Yoshikawa, T. (2013). Involvement of free radicals and oxidative stress in NAFLD/NASH. Free Radical Research, 47(11), 869-880.

Sun, K., Montana, V., Chellappa, K., Brelivet, Y., Moras, D., Maeda, Y., ... Sladek, F. M. (2007). Phosphorylation of a conserved serine in the deoxyribonucleic acid binding domain of nuclear receptors alters intracellular localization. Molecular Endocrinology, 21(6), 1297-1311.

Takaki, A., Kawai, D., \& Yamamoto, K. (2013). Multiple hits, including oxidative stress, as pathogenesis and treatment target in non-alcoholic steatohepatitis (NASH). International Journal of Molecular Sciences, 14(10), 20704-20728.

Tanoli, T., Yue, P., Yablonskiy, D., \& Schonfeld, G. (2004). Fatty liver in familial hypobetalipoproteinemia roles of the APOB defects, intraabdominal adipose tissue, and insulin sensitivity. Journal of Lipid Research, 45(5), 941-947.

Valenti, L., Rametta, R., Dongiovanni, P., Maggioni, M., Fracanzani, A. L., Zappa, M., ... Fargion, S. (2008). Increased expression and activity of the transcription factor FOXO1 in nonalcoholic steatohepatitis. Diabetes, 57(5), 1355-1362.

Walesky, C., Gunewardena, S., Terwilliger, E. F., Edwards, G., Borude, P., \& Apte, U. (2013). Hepatocyte-specific deletion of hepatocyte nuclear factor-4a in adult mice results in increased hepatocyte proliferation. American Journal of Physiology-Gastrointestinal and Liver Physiology, 304(1), G26-G37.

Wheeler, M. D., Kono, H., Yin, M., Rusyn, I., Froh, M., Connor, H. D., .. . Thurman, R. G. (2001). Delivery of the Cu/Zn-superoxide dismutase gene with adenovirus reduces early alcohol-induced liver injury in rats. Gastroenterology, 120(5), 1241.

Yang, X., Zalzala, M., Xu, J., Li, Y., Yin, L., \& Zhang, Y. (2015). A Metabolic Stress-inducible miR-34a-HNF4a Pathway Regulates Lipid and Lipoprotein Metabolism. Nature Communications, 6, $7466-7466$.

Yin, L., Ma, H., Ge, X., Edwards, P. A., \& Zhang, Y. (2011). Hepatic hepatocyte nuclear factor $4 a$ is essential for maintaining triglyceride and cholesterol homeostasis. Arteriosclerosis, Thrombosis, and Vascular Biology, 31(2), 328-336.

\section{SUPPORTING INFORMATION}

Additional Supporting Information may be found online in the supporting information tab for this article.

How to cite this article: Yu D, Chen G, Pan M, et al. High fat diet-induced oxidative stress blocks hepatocyte nuclear factor $4 a$ and leads to hepatic steatosis in mice. J Cell Physiol. 2018;233:4770-4782. https://doi.org/10.1002/jcp.26270 